Research Article

\title{
Comprehensive Evaluation of Operating Speeds for High-Speed Railway: A Case Study of China High-Speed Railway
}

\author{
Jiamin Zhang $\mathbb{D}^{1}$ and Jiarui Zhang ${ }^{2}$ \\ ${ }^{1}$ College of Transportation, Shandong University of Science and Technology, Qingdao 266590, Shandong, China \\ ${ }^{2}$ Qingdao Locomotive Depot, Jinan Bureau of China Railway, Qingdao 266041, Shandong, China \\ Correspondence should be addressed to Jiamin Zhang; zjmsunrise@126.com
}

Received 3 September 2020; Revised 4 January 2021; Accepted 21 January 2021; Published 3 February 2021

Academic Editor: Mariano Torrisi

Copyright (c) 2021 Jiamin Zhang and Jiarui Zhang. This is an open access article distributed under the Creative Commons Attribution License, which permits unrestricted use, distribution, and reproduction in any medium, provided the original work is properly cited.

\begin{abstract}
This paper proposes the indicator systems and integrated desirability framework for comprehensive evaluation towards the operating speeds of high-speed railway (HSR). Speed is a crucial piece in the characterization of the HSR system. The debate about what is the most appropriate operating speed continues. The established indicator systems and integrated desirability framework can comprehensively evaluate the HSR operating speeds from stand points of the economic efficiency, operational efficiency, track capacity, operational security, and environment impact. Moreover, the integrated desirability framework, which is a combination of entropy-analytical hierarchy procedure (EAHP) and technique for order preference by similarity to ideal solution (TOPSIS), can output some references for selecting the most suitable speed regimes of HSR. The application of the desirability framework to the case of China high-speed railway (CHSR) is demonstrated concretely. Based on the case study of CHSR, the comprehensive analysis of the effectiveness of the indicator systems on HSR operating speeds is carried out. The case study shows that the proposed indicator systems and integrated desirability framework can be used to evaluate comprehensively the HSR operating speeds under various conditions.
\end{abstract}

\section{Introduction}

The high-speed railway (HSR) is currently operating in more than 12 countries throughout the world, including China high-speed railway (CSHR), which is changing people's way of life. UIC [1] classified HSR services as those lines running at a minimum of $250 \mathrm{~km} / \mathrm{h}(155 \mathrm{mph})$. Allen and Levinson [2] analyzed on changes in scheduled travel times and average speeds between 1965 and 2015. Givoni [3] defined the high-speed train (HST) services as high capacity and frequency railway services achieving an average speed of over $200 \mathrm{kph}$. China Railway Administration defined CHSR as follows: the newly built railway line, the designed operating speeds of which are more than $250 \mathrm{~km} / \mathrm{h}$; or the passenger dedicated line (PDL), the initial operating speeds of which are not less than $200 \mathrm{~km} / \mathrm{h}$. The multipoints, long distance, and large coverage are the special features of the CHSR network system. Till the end of 2020, the national operating distance of China railways has reached 146300 kilometres, and the CHSR operating distance is more than 37900 kilometres (more than $60 \%$ of its counterpart in the worldwide). The demand for train traffic is increasing worldwide with an ongoing trend. This is also the case in China. To meet this demand, the China mid-long-term railway network plan (2016-2025) aims to build eight-byeight grid CHSR network.

Speed is a crucial piece in the characterization of the HSR system. However, the technical definition of speed is not unique, since it relates to the infrastructural exploitation model chosen by the rail operator. The maximum track speed, i.e., a technical parameter mainly relating to the physical rail infrastructure, determines the radius of the curves and the gradient of the slopes in the design stage. The design standard of CHSR infrastructure includes two speed classes, i.e., $200 \sim 250 \mathrm{~km} / \mathrm{h}$ and $300 \sim 350 \mathrm{~km} / \mathrm{h}$. The maximum operating speed relates to the technical characteristics 
of the trains and the way in which they are operated. This operating speed is only constrained by the maximum track speed. In the 1960s 1980s, it was developed from $210 \mathrm{~km} / \mathrm{h}$ to over $250 \mathrm{~km} / \mathrm{h}$. In the $1980 \mathrm{~s}$ and $1990 \mathrm{~s}$, it was improved from $250 \mathrm{~km} / \mathrm{h}$ to $300 \mathrm{~km} / \mathrm{h}$. Since then, $350 \mathrm{~km} / \mathrm{h}$ has become the general design speed for HSR worldwide. Historically, the maximum operating speed of HSR is $350 \mathrm{~km} / \mathrm{h}$ [4], which emerged in China Beijing-Tianjin intercity line initially in 2008. The commercial speed, i.e., the average travel speed of the train trip, results from dividing the distance by the travel time of the journey. CSHR provides the heterogeneous mobility services with different speeds and stopping patterns, which means different passenger services with varying speed and stopping pattern share the same track system. For certain CHSR lines, e.g., WuhanGuangzhou PDL, on opening, the average operating speed of the nonstop train services reached as high as $90 \%$ of its design speeds.

As one of the operating strategies, also speed is a controversial problem. In this regard, it involves (i) the technical problem, e.g., the traction indicators; (ii) the economic problem, e.g., the cost and benefit; (iii) the social problem, e.g., the social needs; (iv) the security and environment problems. Although Givoni and Banister [5] argued that the operating speed of HSR was a less important element, modern CHSR has transformed China railways into a new, fast, convenient, and fashionable transport mode. In history, the China railway experienced six speed-raising programs between 1997 and 2007. To conserve energy consumption and vehicle maintenance costs, CHSR operating speed has been reduced twice in 2011, i.e., the maximum operating speed was adjusted to $300 \mathrm{~km} / \mathrm{h}, 200 \mathrm{~km} / \mathrm{h}$, and $160 \mathrm{~km} / \mathrm{h}$ for the corresponding design speed of $350 \mathrm{~km} / \mathrm{h}, 250 \mathrm{~km} / \mathrm{h}$, and $200 \mathrm{~km} / \mathrm{h}$ CHSR lines, respectively.

For each time of the speed transition, it has targeted to enhance the supply capacity and the supply structure of the railway service. Particularly, mixed operations with trains of various speeds on the same track is one of the CHSR operating features. China is undergoing the supply-side structural reform. The objectives of CHSR include the following: (i) free the capacity of the conventional railways for freight transportation; (ii) upgrade the passenger service quality and capacity; (iii) alleviate the congestion in previously saturated corridors of rail traffic, e.g., BeijingShanghai; (iv) improve the competence of the areas served by rail. To determine the optimum operating speed for balance, it needs to seek a compromise point among so many factors, e.g., cost and benefit, security, environment, and public travel demand. In 1970s, some European countries determined HSR economic speeds in line with the national situations, e.g., Britain $230 \mathrm{~km} / \mathrm{h}$, French $280-300 \mathrm{~km} / \mathrm{h}$, and Germany $270 \mathrm{~km} / \mathrm{h}$. The most suitable travel speed can be defined in different ways [6]: (i) from the perspective of passengers, it is achieved when the total travel time is as short as possible; (ii) from the perspective of congested railway lines, it is achieved when the headway time is as short as possible; (iii) from the perspective of railway operators, it is a mix of the most suitable travel speed for the passengers and the shortest headway time on the congested lines.
As rail plays a backbone role in providing transport services and meeting mobility demand in most nations, the operating speed of HSR should be paid more attention. The debate about what is the most appropriate operating speed continues. In a contribution to the debate, the indicator systems and integrated desirability framework for comprehensive evaluation are offered in this study. The evaluation framework consists of analytical hierarchy procedure (AHP), entropy, and technique for order preference by similarity to ideal solution (TOPSIS) [7]. The term "comprehensive" implies that it considers various standpoints of passengers, railway operators, and society. The precondition of this research is that the design speed of the civil engineering and the train set have been confirmed. Based on the timetable and operating practice, this study evaluates the continuous commercial speed, by considering a finite number of discrete maximum operating speed alternatives, i.e., $200 \mathrm{~km} / \mathrm{h}, 250 \mathrm{~km} / \mathrm{h}, 300 \mathrm{~km} / \mathrm{h}$, and $350 \mathrm{~km} / \mathrm{h}$, so as to provide the evidences for performance improvement of the CHSR systems. In recent years, China railway operator has updated the timetable almost twice a year; the key time point of which relates to HSR directly is as follows: January 2011 (the time point that the partially slow-down speed decision was made), July 2014 (the time point that the fully slowdown speed decision was made), and June 2016 (the time point that China railway operator decided to implement the supply-side structure reform). To gain a better insight of CHSR operating speeds, in this study, certain representative operating lines are selected from the timetables at each key time point, i.e., Hefei-Nanjing PDL in July 2014 (its design and operating speeds are $250 \mathrm{~km} / \mathrm{h}$ and $200 \mathrm{~km} / \mathrm{h}$, respectively), Shenyang-Dandong PDL in June 2016 (both of its design and operating speed are $250 \mathrm{~km} / \mathrm{h}$ ), Beijing-Shanghai HSR in June 2016 (its design and operating speeds are $350 \mathrm{~km} / \mathrm{h}$ and $300 \mathrm{~km} / \mathrm{h}$, respectively), and WuhanGuangzhou PDL in January 2011 (both of its design and operating speeds are $350 \mathrm{~km} / \mathrm{h}$ ).

The remainder of this paper is organized as follows. A detailed analysis of HSR operating speed factors are presented in Section 2. The indicator systems for comprehensive evaluation of HSR operating speeds are developed inSection 3. An integrated desirability framework for comprehensive evaluation is designed in Section 4. A case study on China HSR is presented to verify the feasibility and validity of this method in Section 5. The last section concludes the paper and discusses future research topics.

\section{Analysis of HSR Operating Speed Factors}

2.1. Station Distribution and Stopping Patterns. A running train has to stop en route for passengers boarding and alighting. The travel speed directly relates to the number of stops. By reducing the stop frequency and dwell time, it can boost the travel speed. However, it would also decrease the service frequency in the station. Meanwhile, the behavior of train halt consumes the rail capacity [8]. The stations distribute at various scales of cities with different distance gap geographically. The train stopping patterns can be classified into such types as all-stop, skip-stop, and large station-stop 
only. The train travel speed varies with the station distribution and stopping patterns [9-11]. According to the HSR operating practice, for an entire round of train trip, the running distance with average train speed should occupy more than $60 \%$ of the total travel distance, while the distance covered by the procedure of acceleration and deceleration around the stops should be controlled below 40\%. The benefits resulting from the high speed on long-interstationdistance HSR lines are greater than those on short-interstation-distance HSR lines [12]. According to the travel speed and stop patterns, the train classification of CHSR network is illustrated in Table 1.

2.2. Braking Distance. Under the same condition of braking performance, the braking distance relates to the operating speed positively. In simple mechanics, the braking distance $\left(S_{b}\right)$ is a function of the speed $(v)$ and the braking retardation $\left(a_{r}\right)$ of HST:

$$
S_{b}=\frac{v^{2}}{2 \cdot a_{r}}
$$

with the given braking retardation $\left(a_{r}\right)$, the HST braking distance varies with the operating speed. Even a slight change in the braking distance can affect the headway distance considerably. In that way, the headway time can be affected by the travel speed, which results in less or more buffer time needed. Less buffer time increases the risk of delay propagation and even the security affairs $[6,13]$. By simulation of the traction, Shi [14] got the EMU's braking distance under different speed schemes for Jilin-Changchun CHSR line.

2.3. Operating Cost. Total operating costs of HSR consist of sales and administration, shunting, train operations (e.g., train service and driving operations/safety), energy, maintenance of way, and maintenance of equipment. The operating cost relating to speeds can be measured in the form of per seat-km or per passenger-km cost, which mainly includes EMU energy consumption, depreciation of fixed assets, and maintenance of fixed assets. Marginal cost of increases in maximum speed (in system design, construction, and operating costs) grows more than proportionally with speed [15]; especially energy consumption increases with speed due to exponential increase of air resistance [12].

Energy consumption relates to the EMU operating speed positively. In any plan, the total energy consumption has to be minimized in an absolute sense. In general, both the unit energy consumption of a train and the depreciation and maintenance cost of fixed assets vary with the speed. Thus, the operating costs per seat-km or per passenger-km increase simultaneously with the speed. The energy consumption is mainly used to overcome the running resistance. The energy costs could be estimated from the average consumption of energy required per kilometer [16-18]. Energy consumption of different class of operating speeds [13] is listed in Table 2.
2.4. Ticket Fares and Value of Travel Time Savings (VTTS). Ticket fares are primarily dependent on the travel distance, trip purpose (e.g., business, leisure), and time of the trip (e.g., peak, off-peak, weekday, or weekend). And, it directly relates to the railway profit. The value of passenger time depends on the category of trip purpose. From the rational economic perspective, the ticket fares positively relate to the operating cost and operating speed. However, the determination of the ticket fares also depends on the attribute or concern of the rail operators [19], involving both the profit of rail agency and the social welfare.

The passenger purchasing power and willingness to pay also have to be considered. The modal share that the HST captures depends mainly on the travel time it offers compared with other modes but also on the travel cost. The ticket fares negatively correlate with the HST ridership. The higher value of the saving times can help HST to attract the timesensitive passenger flows, e.g., those traveling for business. Anyway, in most cases, besides the travel speed, the ticket fares would be one of the key factors when the passengers make decisions about whether or not to choose HST as the travel mode, especially for those price-sensitive groups.

To a great extent, the intention for those who choose HSR as the travel mode is to trade time for money. What they count on is the value of travel time savings (VTTS), which also depends on the value of time per se. For the value of time (VOT), it is too data hungry to be quantified in most cases. This study simplifies the passenger demand into the type of high-end demand and the ordinary demand firstly and then regards the VOT of the former one as four times of the latter one based on the two-eight principle.

2.5. Attractiveness of HST. On the corridor with various parallel transport modes, the main factors that affect the passenger choice include the speed, security, punctuality, economic, comfortable, and convenient [20], besides the purchasing power of passenger and travel purpose. HST is a closer substitute to the plane than the conventional train. Compared with other transport modes, the modal share that the HST captures depends mainly on the travel speed it offers besides the travel cost and the conditions. The relative modal split among conventional railway, high-speed railway, and air passenger transport can be estimated by market share modal like Game Engineering [21-24]. While the absolute passenger ridership/turnover volume of HST can also be gained by field investigation.

2.6. Electric Multiple Unit (EMU) Characteristics. The operating speed of electric multiple unit (EMU) relates to its operating cost positively. The relationship between EMU procurement fee per seat and the maximum operating speed can be defined as follows [25]:

$$
C_{v}=0.1267 v-11.12,
$$

where $C_{v}$ is EMU procurement fee at the maximum operating speed of $v$. 
TABLE 1: Classification of trains on CHSR network.

\begin{tabular}{|c|c|c|}
\hline $\begin{array}{l}\text { Train } \\
\text { classification }\end{array}$ & $\begin{array}{l}\text { Stop ratio } \\
(\%)\end{array}$ & Description \\
\hline Express train & $0 \sim 10$ & $\begin{array}{c}\text { Without intermediate stops or only stopping at large stations, only operating between large cities with } \\
\text { the highest average travel speed }\end{array}$ \\
\hline $\begin{array}{l}\text { Special express } \\
\text { train }\end{array}$ & $20 \sim 30$ & $\begin{array}{c}\text { Stopping only at large stations, with a few intermediate stops, mainly serving the passenger flow between } \\
\text { the large and medium cities }\end{array}$ \\
\hline Fast train & $40 \sim 60$ & $\begin{array}{l}\text { Stopping alternately between large and small stations, with relatively more intermediate stops, } \\
\text { occupying a large percent in CHSR network }\end{array}$ \\
\hline Ordinary train & $80 \sim 100$ & All stop type, with the slowest average travel speed \\
\hline
\end{tabular}

TABLE 2: Energy consumption of different class of operating speeds.

\begin{tabular}{|c|c|c|c|}
\hline Item & $200 \mathrm{~km} / \mathrm{h}$ & $250 \mathrm{~km} / \mathrm{h}$ & $300 \mathrm{~km} / \mathrm{h}$ \\
\hline Kinetic energy (kWh/train) & 308.6 & 482.3 & 694.4 \\
\hline Unit operating resistance $(\mathrm{N} / \mathrm{kN})$ & 8.83 & 12.86 & 17.79 \\
\hline Energy consumed by resistance per train km (kWh) & 17.33 & 25.22 & 34.9 \\
\hline Energy consumed by resistance per 10000 pass km (kWh) & 144.4 & 210.2 & 290.8 \\
\hline Ratio & 1.41 & 2.06 & 2.85 \\
\hline
\end{tabular}

On the other hand, EMU turnover time relates to the operating speed negatively. Thus, with the same headway time between adjacent EMU departures, the number of EMUs (the simplified calculation method is as formula (3)) with the higher speed needed can be less, which makes it possible to reduce the EMU procurement fee:

$$
N=\frac{T}{I}
$$

where $N$ stands for the number of EMU needed, $T$ is the EMU turnover time, and $I$ is the headway time between adjacent EMU departures.

2.7. Travel Time and en Route Time. According to the human-machine engineering, the passenger would feel fatigue if the continuous travel time exceeds 6 hours. Usually, travel time $=$ en route time + access time + egress time, en route time $=$ in-vehicle travel time + dwell time + waiting time. What this research concerns is the HST en route time [10], because the research about the access time and egress time would involve other complex travel environment, e.g., the conditions of the urban transport.

The maximum operating speed of HST has to match with the objective travel time of the passengers. The former one is the essence for less travel time and higher accessibility. China mid-long term railway network plan (2016-2025) proposed the objective travel time by HSR in the form of traffic circles. In most cases, the riding comfortability and convenience of HST can surpass those of car and airplane. The product design of the passenger transport has to follow the variation of its demand. Based on the passenger demand, the classification of HST in CHSR network is illustrated in Table 3.

2.8. Speed Heterogeneity and Network Effects. CHSR is a typical shared-use rail system for trains with different speeds. In the timetable, there are three kinds of HSTs, with
TABLE 3: Classification of HST in CHSR network.

\begin{tabular}{lcc}
\hline Train type & Travel time $(\mathrm{h})$ & Travel distance $(\mathrm{km})$ \\
\hline Short distance & $<1.5$ & $<300$ \\
Medium distance & $1.5 \sim 3$ & $300 \sim 800$ \\
Medium long distance & $3 \sim 5$ & $800 \sim 1500$ \\
Long distance & $5 \sim 8$ & $1500 \sim 2000$ \\
Super long distance & $>8$ & $>2000$ \\
\hline
\end{tabular}

different letters for initial train numbers, i.e., $G$ (high-speed passenger trains), $D$ (EMU passenger trains), and $C$ (intercity passenger trains), respectively. In general, there are four HSR models according to its relationship with conventional services illustrated as Figure 1 [16]. CHSR modes belong to the kind of Model 3 .

A typical feature of the CHSR operating plan is the mixed traffic within the same track line [26, 27], which produces the speed heterogeneity in CHSR network [28]. Speed heterogeneity brought about by mixed train operations is an important issue on shared-use rail corridors [29-31].

It is recognized that difference gap of train speed relates to the rail capacity consumption positively $[2,19,32]$. From the view point of the traffic organization, the match conditions of train speed can impact the line capacity greatly. The larger the speed gap is, the more the capacity would be lost. The speed heterogeneity can not only cut rail capacity [33], but also induce delay because of the network effects [34]. With mixed traffic on unidirectional double-track lines, the overtaking behavior among the faster and slower trains implies restrictions on the timetable and causes delay propagation $[35,36]$ due to the network effects.

2.9. Capacity. The UIC capacity leaflet defined the parameters of capacity consumption in the form of "balance of capacity" (number of trains, average speed, heterogeneity, and stability). Landex [37] added an extra dimension, i.e., 
Model 1: exclusive explotation
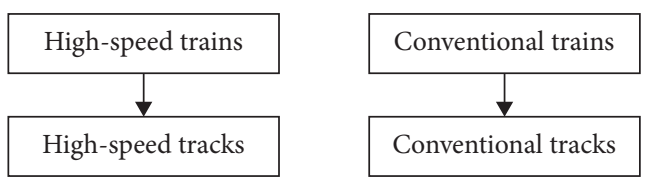

Model 3: mixed conventional

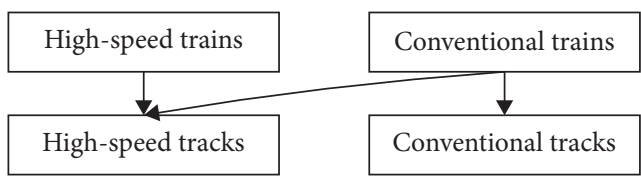

Model 2: mixed high speed

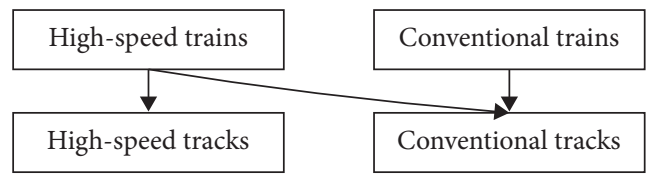

Model 4: fully mixed

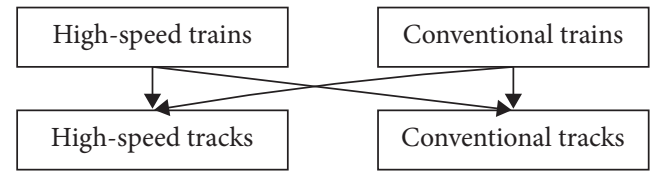

FIGURE 1: HSR models according to relationship with conventional services (source: [16]).

the capacity consumption, to the balance of capacity, which formed the "capacity pyramid" as illustrated in Figure 2.

As far as the speed is concerned, a train consumes a different amount of capacity at different speeds. If a train stands still, the train would consume all the capacity since it occupies the block section for an infinite amount of time. When the train speeds up, it occupies the block section for shorter time whereas more trains can pass the same block section-more capacity is gained. However, when increasing the speed, also the braking distance is increased, which means that the headway distance and headway time are increased whereas capacity is lost. Thus, when decreasing the speed, the braking distance is also decreased which means there would be more resilience left for the improvement of the capacity.

Changing the travel speed is therefore a cheap way to improve the capacity of a bottleneck. From the view point of traffic organization, Landex and Kaas [6] suggested a new method to change/optimize the travel speed to fit the block lengths of the infrastructure, which made it possible to gain more capacity on a railway line. The direct increase in capacity offered by the HST line is due to the higher frequency, which is feasible due to the higher speed and the most up-todate signaling systems that allow relatively short headway between trains without compromising safety, and due to the use of long trains with high seat capacities. The comparison of the amount of the trains that can be operated between HSR and its conventional counterpart over the same temporal-space is demonstrated as Figure 3.

2.10. Safety. The speed of HST is realized through the traction force generated by the wheel-rail adhesion interaction. In theory, with the increase of the HST speed, the wheel-rail adhesion coefficient will be decreased, which affects the safety condition of the HST operation negatively. Thus, the adhesion coefficient can embody the security pressure in different speeds. The empirical equation of the HST adhesion coefficient can be calculated as follows [17]:

$$
\mu=\frac{13.6}{v+85},
$$

where $\mu$ is the wheel-rail adhesion coefficient and $v$ is the HSR operating speed.

Compared with the conventional train, HST has been equipped with the most advanced security and protection systems, e.g., the signaling systems and automatic train control systems. No doubt, all of the advanced systems are the guarantees for the higher reliability and safety performance of HST.

2.11. Track-Side Noise and Vibration. Campos and De Rus [16] calculated the noise as a function of speed $(V)$ in $\mathrm{kph}$ and estimated an OLS regression equation $(r$-squared $=0.81)$ as follows:

$$
\mathrm{dB}(A)_{@ 25 m}=19.94+29.72 \log 0.6 \mathrm{~V} .
$$

HST generates two kinds of noise, i.e., wheel-rail noise and aerodynamic noise. The level of noise is proportional to HST speed. Wheel-rail noise is proportional to $30 \mathrm{log}$ speed and aerodynamic noise is proportional to $60 \mathrm{log}$ speed [38]. The noise level will be increased by $1 \mathrm{~dB}$ when the speed is increased by $10 \mathrm{kmh}$ [17]. Measurements have been made for noise levels of different high-speed train technologies, and the values obtained ranged from 80 to $90 \mathrm{~dB}(A)$ [39]. Only at speeds above $300 \mathrm{kph}$ does aerodynamics become the main source of noise [40]; thus, rolling noise is probably the dominant source of noise.

Connolly and Kouroussis [41] outlined a vibration prediction tool, ScopeRail, capable of predicting in-door noise and vibration, within structures in close proximity to high-speed railway lines. Many national and international metrics have been proposed for railway vibration assessment [41]. Federal Rail Road Administration [42] provided guidance and procedures for the assessment of potential noise and vibration impacts resulting from proposed HST projects, and they redeveloped the software ScopeRail to predict vibration decibels (simply denoted $V \mathrm{~dB}$ ). $\mathrm{VdB}$ of trains can be calculated using the following formula:

$$
V \mathrm{~dB}=20 \log _{10} \frac{v_{\mathrm{rms}}}{v_{0}},
$$




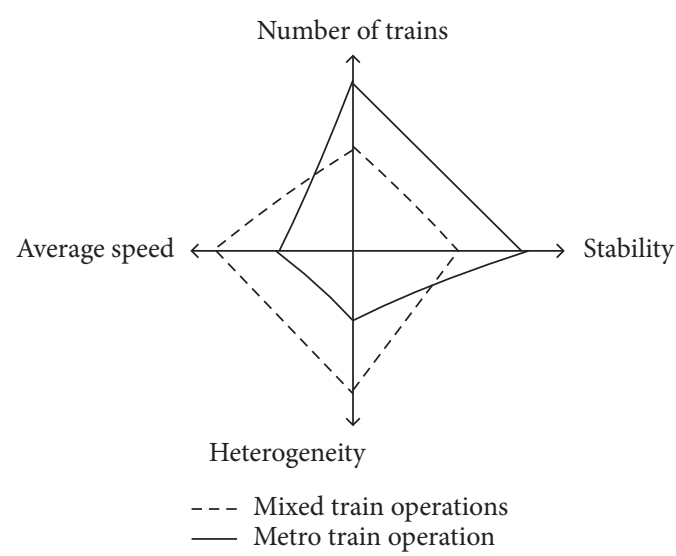

(a)

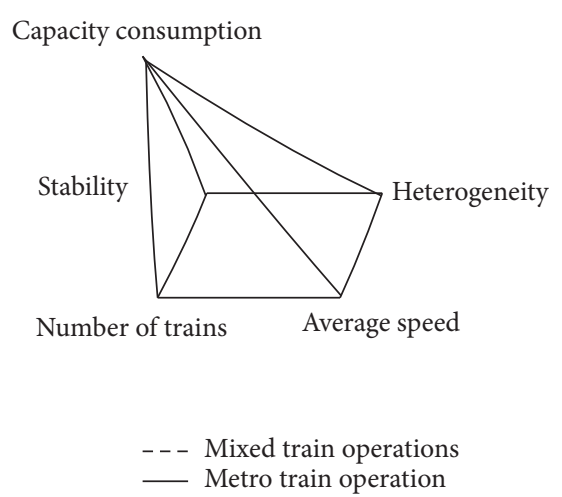

(b)

FIgURE 2: (a) Railway capacity-balance of capacity (a) and (b) the capacity pyramid (b) (source: [37]).

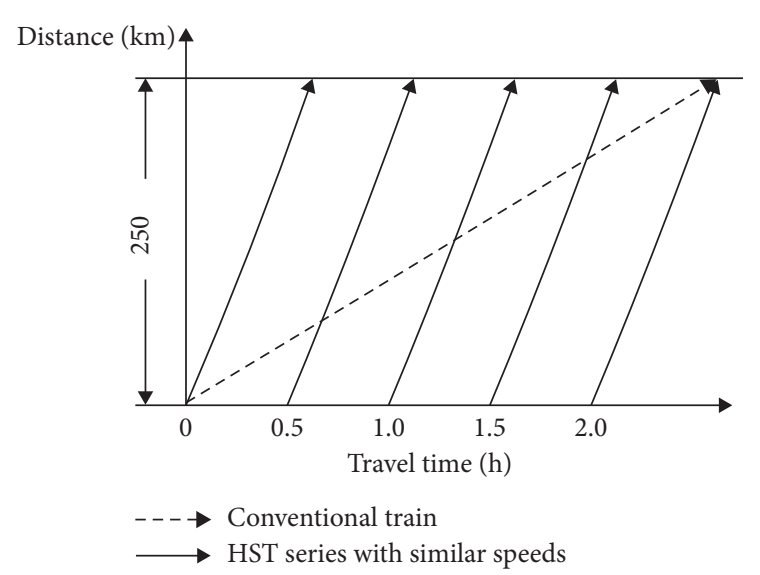

FIGURE 3: Time slots in railways and provision of HSR services (source: [16]).

where $V_{\text {rms }}$ is the moving average of the raw velocity time history and $v_{o}$ is the reference level of background vibration.

\subsection{Perceived Advantages and Disadvantages of Higher-Level} HST Operating Speeds. In summary, the perceived advantages and disadvantages of a higher-level HST speed can be seen in Table 4 . The net balance of these effects depends on the rational decision of the operating speeds.

\section{Indicator Systems for Comprehensive Evaluation}

Indicator systems consist of the factors analyzed above. In this evaluation context, from the standpoint of passengers, railway operators, and society, the evaluation criteria include the economic efficiency, operational efficiency, capacity, security, and environment performance. According to the factors review in Section 2, the indicator systems used in this study are briefly explained as follows, which can be measured in absolute/relative terms.

\subsection{Indicator System of Economic Efficiency}

3.1.1. Running Cost. From the view point of railway operators, the running costs relating to the operating speeds are the sum of the energy consumption, depreciation of the fixed assets, and maintenance cost. The relationship between running cost and operating speed [43] can be aggregated into Table 5.

3.1.2. Travel Cost. From the view point of the passengers, the travel cost depends on the ticket fare rate, travel distance, purchasing power, and willingness to pay. In total, travel cost equals the travel distance multiplies its corresponding ticket fares. The number of seat in the first class of the CHSR vehicle is about 78, and the number of seat in the second class of CHSR vehicle is about 100 . One standard CHSR train consists of 8 vehicles, including one vehicle of the first class and seven vehicles of the second class. Thus, the proportion of the number of seats between the first class and the second class is $2: 13$. The travel cost per $100 \mathrm{~km}$ can be approximated as follows: travel cost per $100 \mathrm{~km}=$ (ticket fare of the first class seat $\times(2 / 15)+$ ticket fare of the second class seat $\times(13 / 15)) \times 100$.

3.1.3. Value of Travel Time Savings (VTTS). The travel purpose for most of the HSR passengers is for public affairs or business. Thus, the main contribution of HSR towards passenger embodies on the form of VTTS, which has to be accurate to hours when estimated. According to the relationship between VTTS and the maximum operating speeds based on the benchmark scheme of $200 \mathrm{~km} / \mathrm{h}$ [43], the calculation method for VTTS can be estimated as follows:

$$
R(t)=Q(t) \cdot r \cdot \Delta C \cdot P(t),
$$

where $Q(t)$ is the passenger volume of CHSR, $\Delta C$ is the travel time savings of the passengers by shifting from conventional railway to CHSR, $r$ is the utilization coefficient relating to travel purpose (e.g., travel for business), $P(t)$ is 
Table 4: Perceived advantages and disadvantages of higher-level HST operating speeds.

\begin{tabular}{lc}
\hline Advantages & Disadvantages \\
\hline More value of travel time savings & Longer braking distance \\
Less enroute time & Higher ticket fare rates \\
Gain much more capacity & More severe noise and vibration \\
Longer operating distance for competition & More operating cost \\
With other modes & Longer stop distance \\
Speed up EMU turnover & Lowesion coefficient between wheel and rail \\
\hline
\end{tabular}

TABLE 5: Relationship between running cost and operating speed.

\begin{tabular}{lcccc}
\hline $\begin{array}{l}\text { Maximum operating } \\
\text { speed }(\mathrm{km} / \mathrm{h})\end{array}$ & $\begin{array}{c}\text { Energy consumption } \\
(100 \text { million yuan })\end{array}$ & $\begin{array}{c}\text { Depreciation of fixed assets } \\
(100 \text { million yuan })\end{array}$ & $\begin{array}{c}\text { Maintenance cost } \\
(100 \text { million yuan })\end{array}$ & Total (100 million yuan) \\
\hline 200 & 36.9 & 60.1 & 58.5 & 155.5 \\
250 & 40.2 & 66.3 & 64.5 & 171 \\
300 & 44.3 & 73.1 & 70.5 & 187.9 \\
350 & 55.8 & 76.3 & 74.2 & 206.6 \\
\hline
\end{tabular}

time value per hour unit, $t$ is the time moment for evaluation, and $R(t)$ is the value of travel time savings (VTTS).

3.1.4. Competitive Travel Distance for HSR. Within 4 hours of running time, HSR is superior to other transport modes. Accordingly, the competitive travel distance for HSR under different maximum operating speeds [17] can be estimated as Table 6.

\subsection{Indicator System of Operational Efficiency}

3.2.1. Percentage of Maximum Operating Speed Achieved. The percentage of maximum operating speed achieved is measured by the average travel speed-to-maximum operating speed ratio. While the average travel speed can be measured through dividing the travel distance in one direction by the travel time, and the travel time includes the running time in the track section and the additional time for HST starting and braking. The variations of CHSR average travel speeds with the maximum operating speeds [17] can be illustrated as Table 7 .

3.2.2. Compatibility of Mixed Traffic. From the view point of technique and operation, it is recognized that it is proper to match the maximum operating speed of $160 \mathrm{~km} / \mathrm{h} \sim 200 \mathrm{~km} /$ $\mathrm{h}$ with that of $300 \mathrm{~km} / \mathrm{h}$ for CHSR. If the maximum operating speed of HST is $350 \mathrm{~km} / \mathrm{h}$, then the speed of the mixed medium-level train should be above $200 \mathrm{~km} / \mathrm{h}$. The compatibility of mixed traffic aims to evaluate the interoperability of the mixed traffic with different speeds, which can be measured in two ways: (i) punctuality of the HST operations, which needs on-the-spot investigation; (ii) the time loss due to the constraints between the train operating lines, which can be measured by the temporal gap between the maximum running time in the timetable and the total average running time achieved through dividing the distance by the average travel speed. Considering the convenience of the data availability, the latter one is adopted for evaluation in this research.
TABle 6: Competitive travel distance for HSR under different maximum operating speeds.

\begin{tabular}{lcccc}
\hline Maximum operating speed $(\mathrm{km} / \mathrm{h})$ & 200 & 250 & 300 & 350 \\
\hline Competitive travel distance $(\mathrm{km})$ & 744 & 900 & 1076 & 1180 \\
\hline
\end{tabular}

TABLE 7: Variations of CHSR average travel speeds with the maximum operating speeds.

\begin{tabular}{lcccc}
\hline Maximum operating speed $(\mathrm{km} / \mathrm{h})$ & 200 & 250 & 300 & 350 \\
\hline $\begin{array}{l}\text { Average travel speed }(\mathrm{km} / \mathrm{h}) \\
\begin{array}{l}\text { Percentage of maximal operating speed } \\
\text { achieved (\%) }\end{array}\end{array}$ & 186 & 225 & 269 & 303 \\
\hline
\end{tabular}

3.3. Indicator System of Track Capacity. CHSR adopts the continuous-speed-curve control mode, which can ensure the successive train operation with high density and frequency. An increase in capacity can be used to increase frequency, shorten travel times, and enlarge buffer time and allowance.

3.3.1. Travel Time. Based on Table 7, the travel time needed per $100 \mathrm{~km}$ can be estimated as Table 8 .

3.3.2. Buffer Time. Buffer time refers to the additional temporal gap between two adjacent trains besides minimum headway time, which can be measured as the equation: buffer time $=$ headway time-minimum headway time. Thus, the buffer time relates to the minimum headway time negatively. The minimum headway time under different maximum operating speed [44] can be estimated as given in Table 9.

3.3.3. Allowance. Allowance refers to the additional time introduced, i.e., by a percentage of minimum running time or a time value. It includes the driver allowance and node allowance [45]. In general, the node allowance is interpreted as extended dwell times. For estimation, allowances $=$ driver 
TABLE 8: Travel time needed per $100 \mathrm{~km}$.

\begin{tabular}{lcc}
\hline $\begin{array}{l}\text { Maximum operating } \\
\text { speed }(\mathrm{km} / \mathrm{h})\end{array}$ & $\begin{array}{c}\text { Average travel } \\
\text { speed }(\mathrm{km} / \mathrm{h})\end{array}$ & Travel time $(\mathrm{min})$ \\
\hline 200 & 186 & 32 \\
250 & 225 & 26 \\
300 & 269 & 22 \\
350 & 303 & 20 \\
\hline
\end{tabular}

TABle 9: Minimum headway time under different maximum operating speed.

\begin{tabular}{lcccc}
\hline Maximal operating speed $(\mathrm{km} / \mathrm{h})$ & 200 & 250 & 300 & 350 \\
\hline Minimum headway time $(\mathrm{min})$ & 3 & $3 \sim 3.5$ & $4 \sim 4.5$ & $4.5 \sim 5$ \\
\hline
\end{tabular}

allowances + node allowances $=$ minimum running time per $200 \mathrm{~km} \times 3 \%+4 \mathrm{~min}$ per $200 \mathrm{~km}$ for node allowances.

3.4. Indicator System of Operational Security. To a certain extent, the wheel-rail adhesion coefficient can characterize the security pressure. According to formula (4), it is calculated as Table 10.

3.5. Indicator System of Environment Impact. The noise and vibration can be considered as the main environment impact from HST operations. The former one can be measured by formula (5), while the latter one can be calculated by formula (6). Usually the impact of vibration can be transformed into that of noise, and in China, much attention has to be paid to the noise impact on the environment. The noise level can be calculated as Table 11 [13].

3.6. Indicator Systems for Comprehensive Evaluation. In summary, the indicator systems for comprehensive evaluation towards the HSR operating speeds can be illustrated as Table 12.

\section{Integrated Desirability Framework for Comprehensive Evaluation}

For evaluation of different alternatives within the same transport mode, e.g., high-speed railway, it is necessary to make a trade-off for identifying the 'best' or most 'preferable' among them. In this study, the integrated desirability framework for comprehensive evaluation can be illustrated as Figure 4. Under the absence of surveys on the opinions of experts and representatives of particular interest groups, weights are determined analytically, by using AHP and entropy methods. Then, the TOPSIS method is applied to evaluate the desirability degree of the operating speeds. Obviously, this framework involves two major procedures, i.e., EAHP (entropy-AHP) process and EAHP-TOPSIS process, both of which are different from the other
TABLE 10: Wheel-rail adhesion coefficient under different operating speeds.

\begin{tabular}{lcccc}
\hline Maximum operating speed $(\mathrm{km} / \mathrm{h})$ & 200 & 250 & 300 & 350 \\
\hline Wheel rail adhesion coefficient & 0.048 & 0.041 & 0.035 & 0.031 \\
\hline
\end{tabular}

Table 11: Noise level under different operating speed.

\begin{tabular}{lllll}
\hline Maximum operating speed $(\mathrm{km} / \mathrm{h})$ & 200 & 250 & 300 & 350 \\
\hline Noise level $(\mathrm{dB})$ & 85.5 & 89.5 & 92.5 & 95.5 \\
\hline
\end{tabular}

conventional AHP and TOPSIS methods. The framework is described in details as follows.

4.1. Steps of EAHP (Entropy-AHP) Process for Determining the Weight Vector. The steps of the entropy-AHP process are as follows:

Step 1. Construct judgement matrix $\bar{R}=\left\{\bar{r}_{i j}\right\}_{n \times n}=$ $\left[\begin{array}{cccc}\bar{r}_{11} & \bar{r}_{12} & \cdots & \bar{r}_{1 n} \\ \bar{r}_{21} & \bar{r}_{22} & \cdots & \bar{r}_{2 n} \\ \vdots & \vdots & \ddots & \vdots \\ \bar{r}_{n 1} & \bar{r}_{n 2} & \cdots & \bar{r}_{n n}\end{array}\right]$, and then calculate initial single hierarchy-sorting vector $\theta=\left(\theta_{1}, \theta_{2}, \ldots, \theta_{m}\right)^{T}$ of the indicators with AHP.

Step 2. Normalize judgement matrix $\bar{R}=\left\{\bar{r}_{i j}\right\}_{n \times n}$ and get normalized matrix $R=\left\{r_{i j}\right\}_{n \times n}=\left[\begin{array}{cccc}r_{11} & r_{12} & \cdots & r_{1 n} \\ r_{21} & r_{22} & \cdots & r_{2 n} \\ \vdots & \vdots & \ddots & \vdots \\ r_{n 1} & r_{n 2} & \cdots & r_{n n}\end{array}\right]$, where $r_{i j}=\bar{r}_{i j} / \sum_{i=1}^{n} \bar{r}_{i j}$.

Step 3. Calculate entropy $E_{j}$ of indicator $j: E_{j}=$ $-(\ln n)^{-1} / \sum_{i=1}^{n} r_{i j} \ln r_{i j}, 0 \leq E_{j} \leq 1$.

Step 4. Calculate deviation degree $d_{j}$ of indicator $j$ : $d_{j}=1-E_{j}$.

Step 5. Calculate information weight $\mu_{j}$ as correction coefficient for indicator $j: \mu_{j}=d_{j} / \sum_{j=1}^{m} d_{j}$.

Step 6. Calculate hierarchy system sort as final weight $\omega_{j}$ for indicator $j$ after correction: $\omega_{j}=\mu_{j} \theta_{j} / \sum_{j=1}^{m} \mu_{j} \theta_{j}$ and get reasonable weight vector $W=\left(\omega_{1}, \omega_{2}, \ldots, \omega_{m}\right)$ for the indicator system.

4.2. Steps of EAHP-TOPSIS Process for Comprehensive Evaluation. Assume $X=\left[x_{1}, x_{2}, \ldots, x_{m}\right]$ as the set of evaluation units, $U=\left[u_{1}, u_{2}, \ldots, u_{n}\right]$ as the set of evaluation indicators, and $W=\left(\omega_{1}, \omega_{2}, \ldots, \omega_{n}\right)^{T}$ as the weight vector, the evaluation value of the evaluation unit $x_{i}$ for indicator $u_{j}$ $(j=1,2, \ldots, n)$ is $a_{i j}$, and then the comprehensive evaluation matrix $A=\left(a_{i j}\right)_{m \times n}$ can be constructed. The steps of EAHP-TOPSIS for comprehensive evaluation are as follows.

Step 1. Normalization. Turn comprehensive evaluation matrix $A=\left(a_{i j}\right)_{m \times n}$ into the normalized matrix $B=\left(b_{i j}\right)_{m \times n}$, where 
TABLE 12: Indicator systems for comprehensive evaluation.

\begin{tabular}{|c|c|c|c|c|c|}
\hline Dimensions/labels & Indicators/labels & Detailed measures & $\begin{array}{l}\text { Speed } \\
\text { arise }\end{array}$ & $\begin{array}{l}\text { Measure } \\
\text { units }\end{array}$ & $\begin{array}{l}\text { Preferred } \\
\text { signs }\end{array}$ \\
\hline \multirow{6}{*}{$\begin{array}{l}\text { Economic } \\
\text { efficiency/ } U_{1}\end{array}$} & \multirow{3}{*}{ Running cost $/ u_{1}$} & Energy consumption & Yes & Yuan & $-^{\mathrm{a}}$ \\
\hline & & Depreciation of fixed assets & Yes & Yuan & $-{ }^{\mathrm{a}}$ \\
\hline & & Maintenance cost & Yes & Yuan & $-{ }^{\mathrm{a}}$ \\
\hline & Travel cost $/ u_{2}$ & Travel cost per $100 \mathrm{~km}$ & Yes & Yuan & $-{ }^{\mathrm{a}}$ \\
\hline & Value of travel time savings $/ u_{3}$ & Value of travel time savings & Yes & Yuan & $++^{\mathrm{b}}$ \\
\hline & Competitive travel distance $/ u_{4}$ & Competitive travel distance & Yes & $\mathrm{km}$ & $\#^{c}$ \\
\hline \multirow{2}{*}{$\begin{array}{l}\text { Operational } \\
\text { efficiency/ } U_{2}\end{array}$} & $\begin{array}{l}\text { Percentage of maximum operating } \\
\text { speed achieved } / u_{5}\end{array}$ & $\begin{array}{l}\text { Average travel speed-to-maximum } \\
\text { operating speed ratio }\end{array}$ & Yes & $\%$ & $++^{\mathrm{b}}$ \\
\hline & Compatibility of mixed traffic/ $u_{6}$ & $\begin{array}{l}\text { Time loss due to constraints between the } \\
\text { train operating lines }\end{array}$ & No & Min & $-{ }^{\mathrm{a}}$ \\
\hline \multirow{3}{*}{ Track capacity/ $U_{3}$} & Travel time $/ u_{7}$ & Travel time per $100 \mathrm{~km}$ & No & Min & $-{ }^{\mathrm{a}}$ \\
\hline & Buffer time $/ u_{8}$ & Minimum headway times & Yes & Min & $-{ }^{\mathrm{a}}$ \\
\hline & Allowances $/ u_{9}$ & Allowances & Yes & $\min$ & $\#^{c}$ \\
\hline $\begin{array}{l}\text { Operational } \\
\text { security } / U_{4}\end{array}$ & Wheel-rail adhesion coefficient $/ u_{10}$ & Wheel-rail adhesion coefficient & No & - & $++^{\mathrm{b}}$ \\
\hline $\begin{array}{l}\text { Environment } \\
\text { impact } / U_{5}\end{array}$ & Noise metric/ $u_{11}$ & Noise level & Yes & $\mathrm{dBA}$ & $-{ }^{\mathrm{a}}$ \\
\hline
\end{tabular}

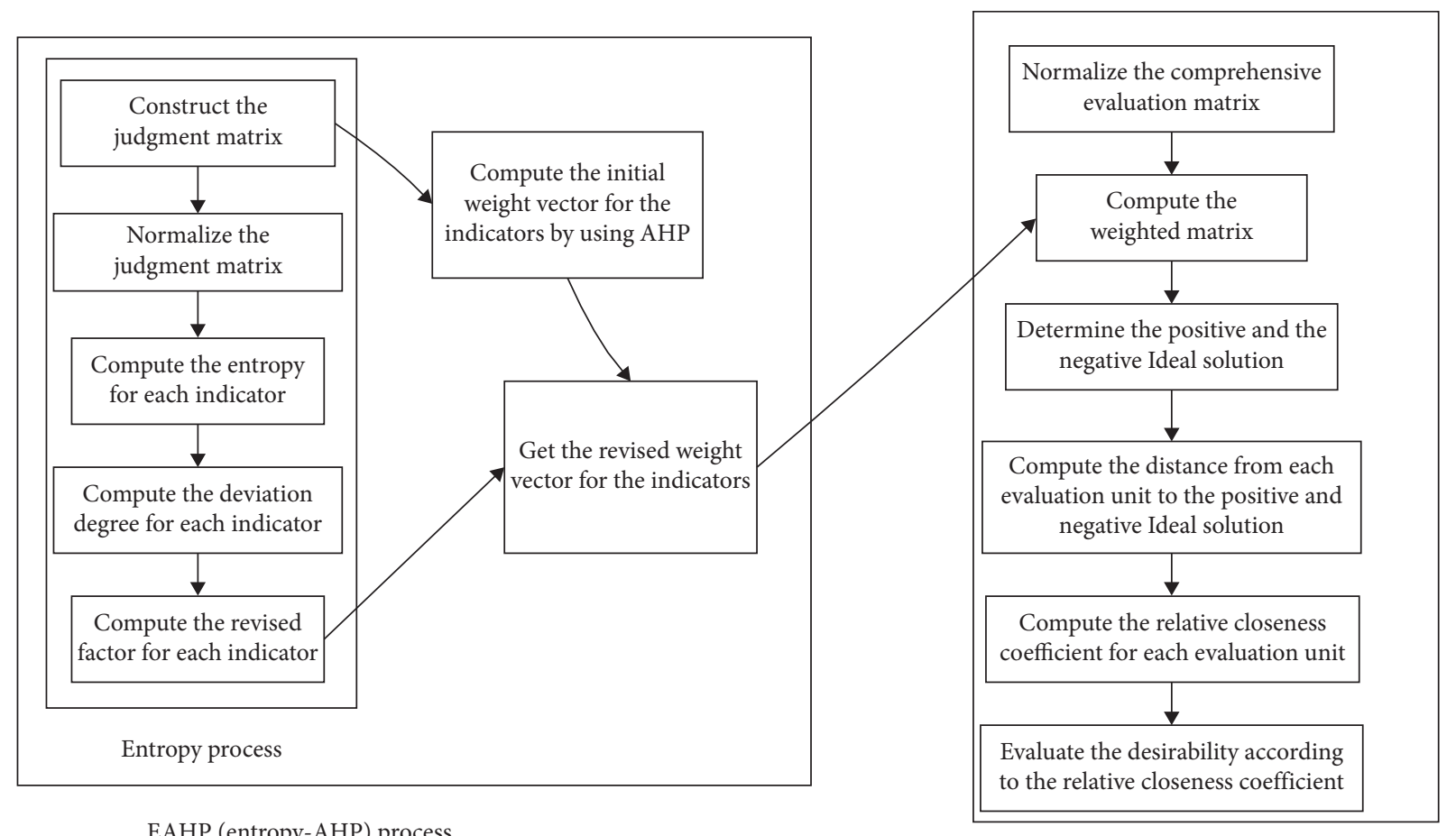

EAHP (entropy-AHP) process

TOPSIS process

FIGURE 4: Integrated desirability framework for comprehensive evaluation. 


$$
b_{i j}= \begin{cases}\frac{a_{i j}-\min _{1 \leq i \leq m}\left\{a_{i j}\right\}}{\max _{1 \leq i \leq m}\left\{a_{i j}\right\}-\min _{1 \leq i \leq m}\left\{a_{i j}\right\}}, & a_{i j} \in \text { indicators of benefit type, } \\ \frac{\max _{1 \leq i \leq m}\left\{a_{i j}\right\}-a_{i j}}{\max _{1 \leq i \leq m}\left\{a_{i j}\right\}-\min _{1 \leq i \leq m}\left\{a_{i j}\right\}}, & a_{i j} \in \text { indicators of cost type } \\ \frac{\max _{1 \leq i \leq m}\left\{\left|a_{i j}-k\right|\right\}-\left|a_{i j}-k\right|}{\max _{1 \leq i \leq m}\left\{\left|a_{i j}-k\right|\right\}}, & a_{i j} \in \text { indicators of fitness type. }\end{cases}
$$

Step 2. Calculate the weighted matrix $Y=\left(y_{i j}\right)_{m \times n}$, where $y_{i j}=\omega_{i} b_{i j}$.

Step 3. Determine the positive and negative ideal solutions. Let $V_{j}^{+}=\max _{1 \leq i \leq m} y_{i j}, V_{j}^{-}=\min _{1 \leq i \leq m} y_{i j}, j=1, \ldots, n$, then the positive ideal solution is $X^{+}=\left(V_{1}^{+}, \ldots, V_{n}^{+}\right)$, and the negative ideal solution is $X^{-}=\left(V_{1}^{-}, \ldots, V_{n}^{-}\right)$.

Step 4. For each evaluation unit, calculate its distance to the positive ideal solution as formula (9):

$$
d_{i}^{+}=d\left(X_{i}, X^{+}\right)=\sqrt{\sum_{j=1}^{n}\left(d_{i j}^{+}\right)^{2},}
$$

where $d_{i j}^{+}=V_{j}^{+}-y_{i j}$ and $j=1, \ldots, n$.

For each evaluation unit, calculate its distance to the negative ideal solution as follows:

$$
d_{i}^{-}=d\left(X_{i}, X^{-}\right)=\sqrt{\sum_{j=1}^{n}\left(d_{i j}^{-}\right)^{2}},
$$

where $d_{i j}^{-}=y_{i j}-V_{j}^{-}$and $j=1, \ldots, n$.

Step 5. For each evaluation unit, i.e., the selected maximum operating speed as $200 \mathrm{~km} / \mathrm{h}, 250 \mathrm{~km} / \mathrm{h}, 300 \mathrm{~km} / \mathrm{h}$, and $350 \mathrm{~km} / \mathrm{h}$, calculate its relative closeness coefficient to the positive ideal solution as formula (11), usually $0 \leq C_{i}^{*} \leq 1$. The desirability degree of the operating speed is positively related to the relative closeness coefficient:

$$
C_{i}^{*}=\frac{d_{i}^{-}}{d_{i}^{-}+d_{i}^{+}}, \quad 1 \leq i \leq m .
$$

Step 6. Evaluate the speed alternatives based on the relative closeness coefficient. The larger the value of the relative closeness coefficient $C_{i}^{*}$ is, the better the desirability degree of the evaluation result is.

\section{Application of the Desirability Framework to the Case of CHSR}

5.1. Determination of Weight Values of Indicator Systems by Using EAHP. According to the indicator systems in Table 12, the AHP hierarchy structure for indicators can be illustrated as Figure 5. Based on Figure 5, the judgement matrix by pairwise comparison can be constructed. And then, the weight values of the indicator systems can be calculated with EAHP (entropy-AHP) process, which is shown in Table13.

\subsection{Results of Comprehensive Evaluation with Desirability Framework}

5.2.1. Comprehensive Evaluation Results in General. Based on CHSR operating practice and the indicator systems, the comprehensive evaluation matrix $\mathrm{A}$ is constructed, in which the row vector represents the evaluation values of the indicators for the selected maximum operating speed alternatives, i.e., $200 \mathrm{~km} / \mathrm{h}, 250 \mathrm{~km} / \mathrm{h}, 300 \mathrm{~km} / \mathrm{h}$, and $350 \mathrm{~km} / \mathrm{h}$. It should be emphasized that some of the raw data are collected from the train schedules, rather than those actually achieved in service, e.g., the value for the indicator $u_{6}$

$$
A=\left[\begin{array}{ccccccccccc}
155.5 & 39.6 & 0 & 744 & 93 & 22 & 32 & 3 & 5.8 & 0.048 & 85.5 \\
171 & 34.8 & 2 & 900 & 90 & 47 & 26 & 3.25 & 5.44 & 0.041 & 89.5 \\
187.9 & 45.8 & 14.3 & 1076 & 89.67 & 75 & 22 & 4.25 & 5.2 & 0.035 & 92.5 \\
206.6 & 49.4 & 31.7 & 1180 & 86.57 & 29 & 20 & 4.75 & 5.02 & 0.031 & 95.5
\end{array}\right] .
$$




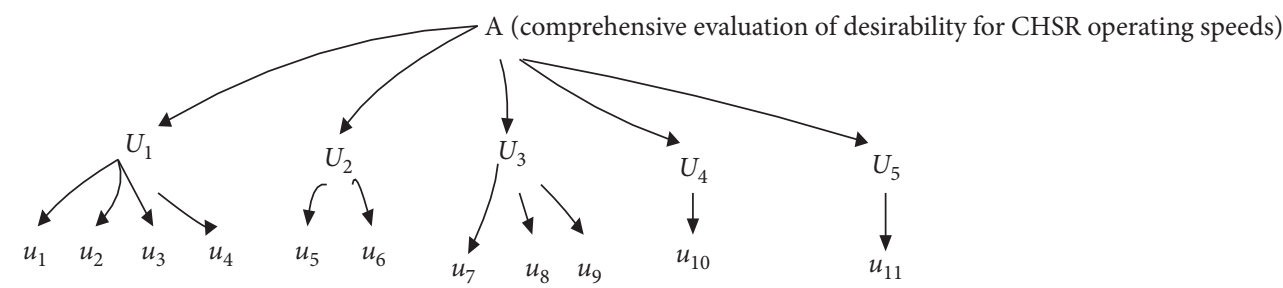

FIgURE 5: AHP hierarchy structure for indicators.

TABLE 13: Weight values of the indicator systems resulting from EAHP (entropy-AHP) process.

\begin{tabular}{|c|c|c|c|c|c|c|c|c|c|}
\hline & $\mathrm{IL}^{\mathrm{a}}$ & $\theta_{j}$ & $\mathrm{ME}^{\mathrm{b}}$ & $\mathrm{CC}^{\mathrm{c}}$ & $E_{j}$ & $d_{j}$ & $\mu_{j}$ & HSSC $^{\mathrm{d}}$ & $\theta_{j}$ \\
\hline \multirow{5}{*}{$A-U$} & $U_{1}$ & 0.086 & \multirow{5}{*}{5.430} & \multirow{5}{*}{0.096} & 0.494 & 0.506 & 0.212 & 0.093 & 0.093 \\
\hline & $U_{2}$ & 0.035 & & & 0.427 & 0.573 & 0.240 & 0.041 & 0.041 \\
\hline & $U_{3}$ & 0.127 & & & 0.541 & 0.459 & 0.193 & 0.130 & 0.130 \\
\hline & $U_{4}$ & 0.525 & & & 0.505 & 0.495 & 0.208 & 0.565 & 0.565 \\
\hline & $U_{5}$ & 0.227 & & & 0.649 & 0.351 & 0.147 & 0.171 & 0.171 \\
\hline \multirow{4}{*}{$U_{1}-u$} & $u_{1}$ & 0.314 & \multirow{4}{*}{4.114} & \multirow{4}{*}{0.042} & 0.679 & 0.321 & 0.217 & 0.276 & 0.026 \\
\hline & $u_{2}$ & 0.139 & & & 0.655 & 0.345 & 0.233 & 0.130 & 0.012 \\
\hline & $u_{3}$ & 0.479 & & & 0.608 & 0.392 & 0.265 & 0.516 & 0.048 \\
\hline & $u_{4}$ & 0.068 & & & 0.576 & 0.424 & 0.286 & 0.078 & 0.007 \\
\hline \multirow{2}{*}{$U_{2}-u$} & $u_{5}$ & 0.750 & \multirow{2}{*}{2} & \multirow{2}{*}{ Consistent } & - & - & - & - & 0.031 \\
\hline & $u_{6}$ & 0.250 & & & - & - & - & - & 0.010 \\
\hline \multirow{3}{*}{$U_{3}-u$} & $u_{7}$ & 0.535 & \multirow{3}{*}{3.009} & \multirow{3}{*}{0.006} & 0.908 & 0.092 & 0.321 & 0.506 & 0.066 \\
\hline & $u_{8}$ & 0.300 & & & 0.875 & 0.125 & 0.436 & 0.379 & 0.049 \\
\hline & $u_{9}$ & 0.165 & & & 0.930 & 0.070 & 0.244 & 0.115 & 0.015 \\
\hline$U_{4}-u$ & $u_{10}$ & 1 & - & - & - & - & - & - & 0.565 \\
\hline$U_{5}-u$ & $u_{11}$ & 1 & - & - & - & - & - & - & 0.171 \\
\hline
\end{tabular}

${ }^{\mathrm{a}}$ Indicator layer, ${ }^{\mathrm{b}}$ maximum eigenvalue, ${ }^{\mathrm{c}}$ consistency check, ${ }^{\mathrm{d}}$ hierarchy single sorting after correction.

By using formula (8), the normalized matrix $B$ can be obtained:

$$
B=\left[\begin{array}{ccccccccccc}
1 & 0.671 & 0 & 0 & 1 & 1 & 0 & 1 & 0 & 1 & 1 \\
0.693 & 1 & 0.063 & 0.675 & 0.533 & 0.528 & 0.5 & 0.857 & 0.828 & 0.588 & 0.6 \\
0.358 & 0.247 & 0.451 & 0.562 & 0.482 & 0 & 0.833 & 0.286 & 0.621 & 0.235 & 0.3 \\
0 & 0 & 1 & 0.113 & 0 & 0.868 & 1 & 0 & 0.207 & 0 & 0
\end{array}\right] .
$$

And then, the weight matrix $Y$ can be determined by using formula $y_{i j}=\omega_{i} b_{i j}$ :

$$
Y=\left[\begin{array}{ccccccccccc}
0.026 & 0.008 & 0 & 0 & 0.031 & 0.01 & 0 & 0.049 & 0 & 0.565 & 0.171 \\
0.018 & 0.012 & 0.003 & 0.005 & 0.017 & 0.005 & 0.033 & 0.042 & 0.012 & 0.332 & 0.103 \\
0.009 & 0.003 & 0.022 & 0.004 & 0.015 & 0 & 0.055 & 0.014 & 0.009 & 0.133 & 0.051 \\
0 & 0 & 0.048 & 0.001 & 0 & 0.009 & 0.066 & 0 & 0.003 & 0 & 0
\end{array}\right]
$$


Furthermore, the positive and negative ideal solution can be achieved, respectively.

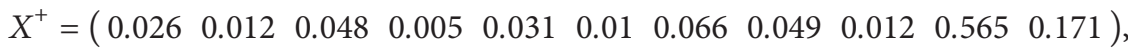

$$
\begin{aligned}
& X^{-}=\left(\begin{array}{lllllllllll}
0 & 0 & 0 & 0 & 0 & 0 & 0 & 0 & 0 & 0 & 0
\end{array}\right) \text {, }
\end{aligned}
$$

Number the maximum operating speed $200 \mathrm{~km} / \mathrm{h}$, $250 \mathrm{~km} / \mathrm{h}, 300 \mathrm{~km} / \mathrm{h}$, and $350 \mathrm{~km} / \mathrm{h}$ as $i=1,2,3$, and 4 , and then calculate the distance to the positive and negative ideal solutions for each evaluation unit as follows:

$$
\begin{aligned}
& {\left[\begin{array}{ccccccccccccc}
i & d_{i 1}^{+} & d_{i 2}^{+} & d_{i 3}^{+} & d_{i 4}^{+} & d_{i 5}^{+} & d_{i 6}^{+} & d_{i 7}^{+} & d_{i 8}^{+} & d_{i 9}^{+} & d_{i, 10}^{+} & d_{i, 11}^{+} & d_{i}^{+} \\
1 & 0 & 0.004 & 0.048 & 0.005 & 0 & 0 & 0.066 & 0 & 0.012 & 0 & 0 & 0.083 \\
2 & 0.008 & 0 & 0.045 & 0 & 0.014 & 0.005 & 0.033 & 0.007 & 0 & 0.233 & 0.068 & 0.25 \\
3 & 0.017 & 0.009 & 0.026 & 0.001 & 0.016 & 0.01 & 0.011 & 0.035 & 0.003 & 0.432 & 0.12 & 0.435 \\
4 & 0.026 & 0.012 & 0 & 0.004 & 0.031 & 0.001 & 0 & 0.049 & 0.009 & 0.565 & 0.171 & 0.594
\end{array}\right],} \\
& {\left[\begin{array}{ccccccccccccc}
i & d_{i 1}^{-} & d_{i 2}^{-} & d_{i 3}^{-} & d_{i 4}^{-} & d_{i 5}^{-} & d_{i 6}^{-} & d_{i 7}^{-} & d_{i 8}^{-} & d_{i 9}^{-} & d_{i, 10}^{-} & d_{i, 11}^{-} & d_{i}^{-} \\
1 & 0.026 & 0.008 & 0 & 0 & 0.031 & 0.01 & 0 & 0.049 & 0 & 0.565 & 0.171 & 0.594 \\
2 & 0.018 & 0.012 & 0.003 & 0.005 & 0.017 & 0.005 & 0.033 & 0.042 & 0.012 & 0.332 & 0.103 & 0.353 \\
3 & 0.009 & 0.003 & 0.022 & 0.004 & 0.015 & 0 & 0.055 & 0.014 & 0.009 & 0.133 & 0.051 & 0.156 \\
4 & 0 & 0 & 0.048 & 0.001 & 0 & 0.01 & 0.066 & 0 & 0.003 & 0 & 0 & 0.082
\end{array}\right] .}
\end{aligned}
$$

Calculate the relative closeness coefficient for CSHR operating speeds as Table 14. From Table 14, it can be seen that under the general comprehensive evaluation condition, the relative closeness coefficient is decreasing with the increasing of the maximum operating speeds, which means that the desirability is decreasing. For the desirability degree of the maximum operating speeds, the highest desirability degree is achieved from $200 \mathrm{~km} / \mathrm{h}$, i.e., 0.8774; the second one is obtained from $250 \mathrm{~km} / \mathrm{h}$, i.e., 0.5854 ; and the lowest one results from $350 \mathrm{~km} / \mathrm{h}$, i.e., only 0.1213 .

\subsubsection{Evaluation Results with Ensured Operational Security.} From Table 13, it can be seen that the operational security indicator $u_{10}$ has the greatest weight which may affect the evaluation results drastically. Thus, assume that the security condition can be ensured, and then evaluate the other indicators comprehensively. The results are shown in Table 15. Under the ensured security condition, for the desirability degree of the maximum operating speed, the highest desirability degree still corresponds to the speed of $200 \mathrm{~km} / \mathrm{h}$, i.e., 0.6880; the second one corresponds to the speed of $300 \mathrm{~km} / \mathrm{h}$, i.e., 0.6029 . Except the desirability degree corresponding to the speed of $200 \mathrm{~km} / \mathrm{h}$, all the other desirability degrees have been improved, the greatest one is achieved from $300 \mathrm{~km} / \mathrm{h}$. The desirability degree of $350 \mathrm{~km} / \mathrm{h}$ is $t$ still the lowest one (i.e., 0.3094), but it has been improved by 0.1881 .
5.2.3. Evaluation Results for Individual Dimensions. Because of the different weights, it is necessary to evaluate the desirability from the individual dimensions, i.e., $U_{1}$ (economic efficiency), $U_{2}$ (operational efficiency), and $U_{3}$ (track capacity).

(i) To evaluate from the dimension of $U_{1}$ (economic efficiency), the results are achieved as Table 16. From the dimension of economic efficiency, the maximum operating speed $350 \mathrm{~km} / \mathrm{h}$ achieves the best desirability degree (i.e., 0.6234 ), the second one is obtained from $300 \mathrm{~km} / \mathrm{h}$ (i.e., 0.4286 ), while the lowest one is got from $250 \mathrm{~km} / \mathrm{h}$ (i.e., $0.3235)$.

(ii) To evaluate from the dimension of $U_{2}$ (operational efficiency), the results are achieved as Table 17. In this respect, the maximum operating speed $200 \mathrm{~km} / \mathrm{h}$ achieves the best desirability degree (i.e., 1), the second one is achieved from $250 \mathrm{~km} / \mathrm{h}$ (i.e., 0.5455), while the lowest one is obtained from $350 \mathrm{~km} / \mathrm{h}$ (i.e., 0.2439).

(iii) To evaluate from the dimension of $U_{3}$ (track capacity), the results are achieved as Table 18 . From this respect, the maximum operating speed $250 \mathrm{~km} / \mathrm{h}$ achieves the best desirability (i.e., $0.6180)$, the second one is achieved from $300 \mathrm{~km} / \mathrm{h}$ (i.e., 0.6060), while the lowest one is got from $200 \mathrm{~km} / \mathrm{h}$ (i.e., 0.4224). 
TABLE 14: Relative closeness coefficient for CSHR operating speeds.

\begin{tabular}{lcccc}
\hline Maximum operating speeds $(\mathrm{km} / \mathrm{h})$ & 200 & 250 & 300 & 350 \\
\hline Relative closeness coefficient & 0.8774 & 0.5854 & 0.2640 & 0.1213 \\
\hline
\end{tabular}

TABLE 15: Evaluation results under ensured security condition.

\begin{tabular}{lcccc}
\hline & $d_{1}^{+}=0.083$ b & $d_{2}^{+}=0.090$ & $d_{3}^{+}=0.054$ & $d_{4}^{+}=0.183$ \\
& $d_{1}^{-}=0.183$ & $d_{2}^{-}=0.120$ & - & $d_{3}^{-}=0.082$ \\
\hline$C_{200}{ }^{\mathrm{a}}$ & 0.6880 & - & - & - \\
$C_{250}$ & - & 0.5714 & 0.6029 & - \\
$C_{300}$ & - & - & - & 0.3094 \\
$C_{350}$ & - & - & - & $d^{-}$ \\
\hline
\end{tabular}

${ }^{\mathrm{a}} \mathrm{C}_{200}$ represents the relative closeness coefficient for the maximum operating speed $200 \mathrm{~km} / \mathrm{h},{ }^{\mathrm{b}} d_{1}^{+}$represents the distance to the positive ideal solution for the maximum operating speed $200 \mathrm{~km} / \mathrm{h}, d_{1}^{-}$represents the distance to the negative ideal solution for the maximum operating speed $200 \mathrm{~km} / \mathrm{h}$, and so on.

TABLE 16: Evaluation results from the dimension of $U_{1}$ (economic efficiency).

\begin{tabular}{|c|c|c|c|c|}
\hline & $\begin{array}{l}d_{1, U_{1}}^{+}=0.048 \\
d_{1, U_{1}}^{-}=0.027\end{array}$ & $\begin{array}{l}d_{2, U_{1}}^{+}=0.046 \\
d_{2, U_{1}}^{-}=0.022\end{array}$ & $\begin{array}{l}d_{3, U_{1}}^{+}=0.032 \\
d_{3, U_{1}}^{-}=0.024\end{array}$ & $\begin{array}{l}d_{4, U_{1}}^{+}=0.029 \\
d_{4, U_{1}}^{-}=0.048\end{array}$ \\
\hline$C_{200}$ & 0.36 & - & - & - \\
\hline$C_{250}$ & - & 0.3235 & - & - \\
\hline$C_{300}$ & - & - & 0.4286 & - \\
\hline$C_{350}$ & - & - & - & 0.6234 \\
\hline
\end{tabular}

TABLE 17: Evaluation results from the dimension of $U_{2}$ (operational efficiency).

\begin{tabular}{|c|c|c|c|c|}
\hline & $\begin{array}{l}d_{1, U_{2}}^{+}=0 \\
d_{1, U_{2}}^{-}=0.033\end{array}$ & $\begin{array}{l}d_{2, U_{2}}^{+}=0.015 \\
d_{2, U_{2}}^{-}=0.018\end{array}$ & $\begin{array}{l}d_{3, U_{2}}^{+}=0.019 \\
d_{3, U_{2}}^{-}=0.015\end{array}$ & $\begin{array}{l}d_{4, U_{2}}^{+}=0.031 \\
d_{4, U_{2}}^{-}=0.01\end{array}$ \\
\hline$C_{200}$ & 1 & - & - & - \\
\hline$C_{250}$ & - & 0.5455 & - & - \\
\hline$C_{300}$ & - & - & 0.4412 & - \\
\hline$C_{350}$ & - & - & - & 0.2439 \\
\hline
\end{tabular}

TABLE 18: Evaluation results from the dimension of $U_{3}$ (track capacity).

\begin{tabular}{|c|c|c|c|c|}
\hline & $\begin{array}{l}d_{1, U_{3}}^{+}=0.067 \\
d_{1, U_{3}}^{-}=0.049\end{array}$ & $\begin{array}{l}d_{2, U_{3}}^{+}=0.034 \\
d_{2, U_{3}}^{-}=0.055\end{array}$ & $\begin{array}{l}d_{3, U_{3}}^{+}=0.037 \\
d_{3, U_{3}}^{-}=0.057\end{array}$ & $\begin{array}{l}d_{4, U_{3}}^{+}=0.05 \\
d_{4, U_{3}}^{-}=0.066\end{array}$ \\
\hline$C_{200}$ & 0.4224 & - & - & - \\
\hline$C_{250}$ & - & 0.6180 & - & - \\
\hline$C_{300}$ & - & - & 0.6064 & - \\
\hline$C_{350}$ & - & - & - & 0.5690 \\
\hline
\end{tabular}

\subsection{Discussion of the Evaluation Results}

5.3.1. Major Findings of the Proposed Work on the Application Case. The resulting data in Tables 14-18 show the desirability degree for various speeds from different aspects. The speed line chart (Figure 6) can be achieved by combining all the above evaluation results together. From this chart, the desirability degree changes in speeds can be compared when evaluated from different stand points.

For the maximum operating speed $200 \mathrm{~km} / \mathrm{h}$, it achieves the best desirability degree in terms of operational efficiency and also its general comprehensive evaluation is desirable. For the maximum operating speed $250 \mathrm{~km} / \mathrm{h}$ and $300 \mathrm{~km} / \mathrm{h}$, both of them achieve the best desirability degree in terms of track capacity. For the maximum operating speed $350 \mathrm{~km} / \mathrm{h}$, it achieves the best desirability degree in terms of economic efficiency and also its performance in terms of track capacity is desirable.

From the above resulting data analysis, certain judgements can be made for decisions under current circumstance of CHSR operating and management system: (i) the maximum operating speed $200 \mathrm{~km} / \mathrm{h}$ should be endowed the first priority when making selection decisions in general; secondly $250 \mathrm{~km} / \mathrm{h}$. (ii) With the ensured security condition, both $200 \mathrm{~km} / \mathrm{h}$ and $300 \mathrm{~km} / \mathrm{h}$ can be considered with high priority. (iii) When focusing on the desirability degree of 


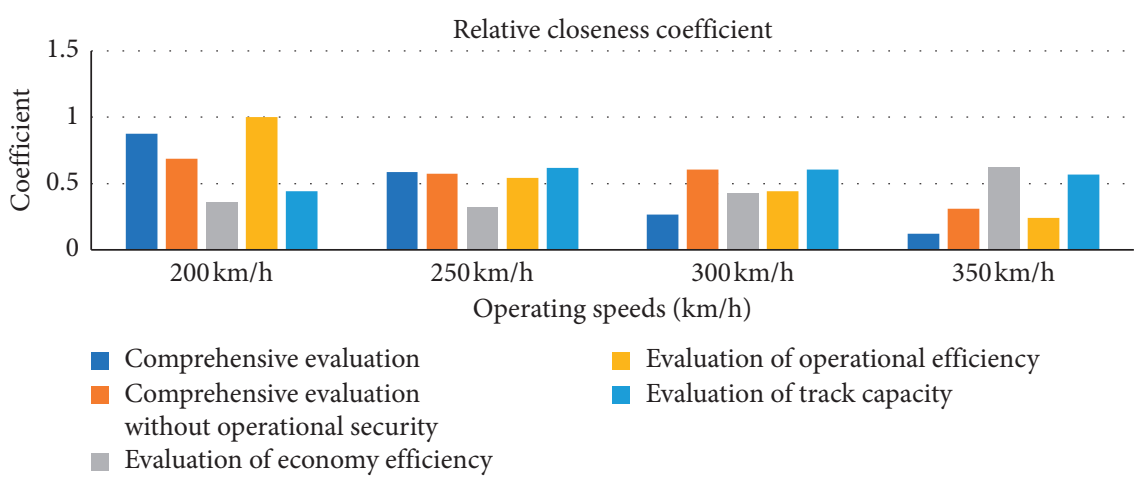

FIGURE 6: Combined evaluation results of operating speeds for CHSR.

economic efficiency dimension, the scheme of $350 \mathrm{~km} / \mathrm{h}$ firstly can be selected and then $300 \mathrm{~km} / \mathrm{h}$. When focusing on the desirability degree of operational efficiency dimension, the schemes of $200 \mathrm{~km} / \mathrm{h}$ and $250 \mathrm{~km} / \mathrm{h}$ can be selected sequentially. When focusing on the desirability degree of track capacity dimension, the schemes of $250 \mathrm{~km} / \mathrm{h}$ and $300 \mathrm{~km} / \mathrm{h}$ can be selected sequentially.

5.3.2. Advantages of the Proposed Work. Aydin et al. [46] provided a hierarchical customer satisfaction framework to measure rail transit line's performances in Istanbul, which is a combination of statistical analysis, fuzzy analytic hierarchy process [47], trapezoidal fuzzy sets [48], and Choquet integral. Salvato et al. [49] applied the conventional AHP method to determine the significance of the parameters that attract more passengers to the rail transport, which allows us to determine normalized weights of particular criteria in their relation to other criteria, based on pairwise comparison of criteria. There are also other evaluation tools and methods like cost-benefit analysis (CBA), cost-effectiveness analysis (CEA) [50], DEA (data envelope analysis), SD (system dynamics) model, logistics framework, value engineering, net present value, and fuzzy inference approach. Compared with these methods, the capabilities of the integrated desirability framework for comprehensive evaluation proposed in this study, i.e., a combination of AHP, entropy [51], and TOPSIS [52], can fulfill the following requirements specially:

(i) Incorporation of the approximate nature of investigation and imprecise data.

(ii) Aggregation of different measured indicators to achieve a composite measure for desirability.

(iii) Improving the efficiency, precision, and operability of the evaluation procedures and results to a great extent.

What should be specially pointed out is that, by using this comprehensive evaluation method, although results indicate that the general desirability degree of $300 \mathrm{~km} / \mathrm{h}$ and $350 \mathrm{~km} / \mathrm{h}$ are not very outstanding yet, the scheme of $350 \mathrm{~km} / \mathrm{h}$ could perform best in terms of economic efficiency, while the scheme of $300 \mathrm{~km} / \mathrm{h}$ has outperformed others in terms of track capacity. As well as known that the construction standard of CHSR system is very high, it is far from speed saturation currently. Considering the features of CHSR operating status, it is necessary to be more pragmatic to synergize among the different speed classes by regarding the maximum operating speeds as the benchmark, so as to form a rational speed regime and exert the CHSR potency fully as possible as it can [53]. In the long run, it needs the joint efforts between the railway operators and researchers to enforce the desirable changes.

\section{Conclusions and Future Studies}

This paper proposes the indicator systems and integrated desirability framework for comprehensive evaluation of the HSR operating speeds. The HSR operating speed factors, i.e., station distribution and stopping patterns, braking distance, operating cost, ticket fares and value of travel time savings, attractiveness of HST, electric multiple unit (EMU) characteristics, travel time and en route time, speed heterogeneity and network effects, capacity, safety, track-side noise, and vibration are analyzed firstly in the comprehensive evaluation.

The indicator systems for comprehensive evaluation of HSR operating speeds are built from the perspective of economic efficiency (i.e., running cost, travel cost, and value of travel time savings), operational efficiency (i.e., percentage of maximum operating speed achieved and compatibility of mixed traffic), track capacity, operational security, and environment impact.

The integrated desirability framework for comprehensive evaluation is proposed, which is a combination of entropy-analytical hierarchy procedure (EAHP) and technique for order preference by similarity to ideal solution (TOPSIS). This framework consists of EAHP (entropyAHP) process and EAHP-TOPSIS process. In the EAHP process, the detailed steps are developed for determining the weight vector of the indicator systems. In this process, the conventional AHP method is modified by entropy. In the EAHP-TOPSIS process, the detailed steps are designed for comprehensive evaluation of the HSR operating speeds. In this process, the conventional TOPSIS method is modified by the EAHP.

A case study to comprehensive evaluation towards China HSR (CHSR) operating speeds is presented. The results show the following: (i) for the desirability degree of the maximum 
operating speeds in general, the highest desirability degree is achieved from $200 \mathrm{~km} / \mathrm{h}$, i.e., 0.8774 . (ii) Under the ensured security condition, the highest desirability degree corresponds to the speed of $200 \mathrm{~km} / \mathrm{h}$, i.e., 0.6880 . (iii) From the dimension of economic efficiency, the maximum operating speed $350 \mathrm{~km} / \mathrm{h}$ achieves the best desirability degree, i.e., 0.6234. (iv) From the dimension of operational efficiency, the maximum operating speed $200 \mathrm{~km} / \mathrm{h}$ achieves the best desirability degree, i.e., 1. (v) From the dimension of operational efficiency, the maximum operating speed $250 \mathrm{~km} / \mathrm{h}$ achieves the best desirability degree, i.e., 0.6180. The above results show that the indicator systems and integrated desirability framework are instructive for seeking the most suitable HSR operating speeds from various perspectives.

In the future research, we will study the train trajectory optimization based on the indicator systems and integrated desirability framework in this paper, which is a more challenging work. Moreover, in nature, the method proposed in this study belongs to the kind of multicriteria decision-making (MCDM) methodology [54], which can also be used to evaluate the given alternatives/solutions for decision purposes.

\section{Data Availability}

The data used to support the findings of this study have been included within this article.

\section{Disclosure}

This research did not receive any specific grant from funding agencies in the public, commercial, or not-for-profit sectors.

\section{Conflicts of Interest}

The authors declare that there are no conflicts of interest regarding the publication of this paper.

\section{Acknowledgments}

We wish to thank the authors of the articles mentioned in the reference list.

\section{References}

[1] UIC - High Speed Department, High-speed and the City, pp. 27-50, France: Union Internationale de Chemin de Fer, Paris, France, 2010.

[2] J. G. Allen and H. S. Levinson, "What happened to speed?: scheduled speeds and travel times of north American passenger trains," Transport Research Record, vol. 2546, no. 1, pp. $60-68,2016$.

[3] M. Givoni, "Development and impact of the modern highspeed train: a review," Transport Reviews, vol. 26, no. 5, pp. 593-611, 2006.

[4] R. Takagi, "High speed railways: the last 10 years," Japan Railway \& Transport Review, vol. 40, pp. 4-7, 2005.

[5] M. Givoni and D. Banister, "Speed: the less important element of the High-Speed Train," Journal of Transport Geography, vol. 22, pp. 5-20, 2012.
[6] A. Landex and A. H. Kaas, "Planning the most suitable travel speed for high frequency railway lines," in Proceedings of the 1st International Seminar on Railway Operations Modelling and Analysis, pp. 1-16, Delft, Netherland, January 2005.

[7] H. Garg, Z. Ali, and T. Mahmood, "Algorithms for complex interval-valued q-rung orthopair fuzzy sets in decision making based on aggregation operators," AHP, and TOPSIS," Expert Systems, vol. 1, p. 2020, Article ID e12609.

[8] J. W. H. M. Goossens, C. P. M. Hoesel, and L. G. Kroon, Optimising Halting Station of Passenger Railway Lines, Meteor, Maastricht Research School of Economics of Technology and Organizations, Netherlands, 2004.

[9] O. Lindfeldt, "An analysis of double-track railway line capacity," Transportation Planning and Technology, vol. 34, no. 4, pp. 301-322, 2011.

[10] X. Xiao and B. Gu, "Study on the speed target evaluation method of intercity railway based on the functional orientation," China Transportation Review, vol. 37, no. 3, pp. 64-71, 2015.

[11] B. Tian, Research on Technical Standards of Basic Elements in Train Diagram for High-Speed Railway, Ph.D. Thesis, Southwest Jiaotong University., Chengdu, China, 2009.

[12] V. R. Vuchic and J. M. Casello, "An evaluation of maglev technology and its comparison with high speed rail," Transport Quarterly, vol. 56, no. 2, pp. 33-45, 2002.

[13] X. Rao and Y. Guo, "Influential factors over intercity railway speed target value in urban agglomeration," Journal of Urban Rail Transit, vol. 8, pp. 5-9, 2013.

[14] W. Shi, "Selection of target values of time and speed for Changchun-Jilin Intercity rail," Journal of Rail Engineer Society, vol. 7, pp. 10-14, 2006.

[15] G. Li and B. Shuai, "Analysis on cost curve of railway passenger dedicated lines," Journal of Railway Transport and Economy, vol. 28, no. 5, pp. 1-3, 2006.

[16] J. Campos and G. De Rus, "Some stylized facts about highspeed rail: a review of HSR experiences around the world," Transport Policy, vol. 16, no. 1, pp. 19-28, 2009.

[17] B. Hu, The Study of Relationship between the Target Speed of China's High Speed Railway and Market Share, Ph.D. Thesis, China Academy of Railway Sciences, Beijing, China, 2012.

[18] W. Liu, Research on Main Engineering Economics Problems of Chinese High-Speed Passenger-Only Guided Transport System, Ph.D. Thesis, Southwest Jiaotong University, Chengdu, China, 2002.

[19] A. Talebian, Planning Passenger Rail Services in a Competitive and Shared-Use Environment, Ph.D. Thesis, University of Illinois at Chicago, Chicago, USA, 2016.

[20] H. Y. Su, W. C. Tao, and X. L. Hu, "A line planning approach for high-speed rail networks with time-dependent demand and capacity constraints," Mathematical Problems in Engineering, vol. 2019, Article ID 7509586, 18 pages, 2019.

[21] N. Adler, C. Nash, and E. A. Pels, High-speed Rail \& Air Transport Competition: Game Engineering as Tool for CostBenefit Analysis, Tinbergen Institute Discussion Paper, Netherland, 2008.

[22] C. Román, R. Espino, and J. C. Martín, “Analyzing competition between the high speed train and alternative modes. The case of the madrid-zaragoza-barcelona corridor," Journal of Choice Modelling, vol. 3, no. 1, pp. 84-108, 2010.

[23] G. de Rus Mendoza, Economic Analysis of High Speed Rail in Europe, Fundacion BBVA, Bilbao, Spanish, 2012.

[24] A. S. Bergantino, C. Capozza, and M. Capurso, "The impact of open access on intra- and inter-modal rail competition. A 
national level analysis in Italy," Transport Policy, vol. 39, pp. 77-86, 2015.

[25] C. Ma, Research on High Speed Railway's Transportation Cost, M. S. thesis, Southwest Jiaotong University, Chengdu, China, 2012.

[26] J. Zhang, "Analysis on comprehensive balance of train operation plan for high speed railway under mixed traffic condition," in Proceedings of 2011 IEEE International Conference on Service Operations, Logistics, and Informatics, pp. 397-342, Beijing, China, July 2011.

[27] J. Zhang, "Analysis on line capacity usage for China high speed railway with optimization approach," Transportation Research Part A: Policy and Practice, vol. 77, pp. 336-349, 2015.

[28] J. Warg, Timetable Evaluation with Focus on Quality for Travelers, Ph.D. Thesis, KTH Royal Institute of Technology, Stockholm, Sweden, 2016.

[29] M. H. Dingler, Y.-C. Lai, and C. P. L. Barkan, "Impact of train type heterogeneity on single-track railway capacity," Transportation Research Record: Journal of the Transportation Research Board, vol. 2117, no. 1, pp. 41-49, 2009.

[30] M. H. Dingler, The Impact of Operational Strategies and New Technologies on Railroad Capacity, M. S. thesis, University of Illinois at Urbana-Champaign, Champaign, IL, USA, 2010.

[31] S. L. Sogin, C. T. Dick, Y. C. Lai, and C. P. Barkan, "Analyzing the Progression From Single to Double Track Networks," pp. 1-9, American Society of Mechanical Engineers (ASME), Boston, MA, USA, 2013.

[32] T. Huisman and R. J. Boucherie, "Running times on railway sections with heterogeneous train traffic," Transportation Research Part B: Methodological, vol. 35, no. 3, pp. 271-292, 2001.

[33] S. Harrod, "Capacity factors of a mixed speed railway network," Transportation Research Part E: Logistics and Transportation Review, vol. 45, no. 5, pp. 830-841, 2009.

[34] A. Landex and O. A. Nielsen, "Network effects in railways," Computers in Railways XIII: Computer System Design and Operation in the Railway and Other Transit Systems, pp. 391-401, Southampton, UK, 2012.

[35] O. Lindfeld, Railway Operation Analysis, Ph.D. Thesis, KTH Royal Institute of Technology, Stockholm, Sweden, 2010.

[36] S. Gibson, G. Cooper, and B. Ball, "Developments in transport policy: the evolution of capacity charges on the UK rail network," Journal of Transport Economics and Policy, vol. 36, no. 2, pp. 341-354, 2002.

[37] A. Landex, Methods to Estimate Railway Capacity and Passenger Delays, Ph.D. thesis, Technical University of Denmark, Copenhagen, Denmark, 2008.

[38] C. Hanson, "High-speed rail system noise assessment," Transport Research Record, vol. 1255, pp. 119-121, 1999.

[39] G. De Rus, Economic Evaluation of the High Speed Rail, Expert Group on Environmental Studies, Ministry of Finance, Scotland, Sweden, 2012.

[40] M. Brons, P. Nijkamp, E. Pels, and P. Rietveld, "Railroad noise: economic valuation and policy," Transportation Research Part D: Transport and Environment, vol. 8, no. 3, pp. 169-184, 2003.

[41] D. P. Connolly, G. Kouroussis, P. K. Woodward, A. Giannopoulos, O. Verlinden, and M. C. Forde, "Scoping prediction of re-radiated ground-borne noise and vibration near high speed rail lines with variable soils," Soil Dynamics and Earthquake Engineering, vol. 66, pp. 78-88, 2014.

[42] C. E. Hanson, J. C. Ross, D. A. Towers, and M. Harris, Highspeed Ground Transportation Noise and Vibration Impact
Assessment, United States, Federal Railroad Administration, Office of Railroad Policy and Development, Washington, DC, USA, 2012.

[43] Q. Fang, "Research and application of technical and economic analysis method in passenger special line targeted speed," Journal of Railway Science and Engineering, vol. 3, no. 6, pp. 74-79, 2006.

[44] C. Tian, S. Zhang, Y. S. Zhang, and X. L. Jiang, "Study on the train headway on automatic block sections of high speed railway," Journal the China Railway Society, vol. 37, no. 10, pp. 1-6, 2015.

[45] H. Sipilä, Simulation of Rail Traffic: Methods for Timetable Construction, Delay Modeling and Infrastructure Evaluation, Ph.D. thesis, KTH Royal Institute of Technology, Stockholm, Sweden, 2015.

[46] N. Aydin, E. Celik, and A. T. Gumus, "A hierarchical customer satisfaction framework for evaluating rail transit systems of Istanbul," Transportation Research Part A: Policy and Practice, vol. 77, pp. 61-81, 2015.

[47] S. Niroomand, H. Garg, and A. Mahmoodirad, "An intuitionistic fuzzy two stage supply chain network design problem with multi-mode demand and multi-mode transportation," ISA Transactions, vol. 107, pp. 117-133, 2020.

[48] A. Mahmoodirad, H. H. G. Ali, and S. S. Niroomand, "Solving fuzzy linear fractional set covering problem by a goal programming based solution approach," Journal of Industrial \& Management Optimization, vol. 13, no. 5, pp. 1-18, 2017.

[49] J. A. Salvato, N. L. Nemerow, and F. J. Agardy, Environmental Engineering, pp. 108-125, John Wiley \& Sons, Hoboken, NJ, USA, 2003.

[50] D. Browne and L. Ryan, "Comparative analysis of evaluation techniques for transport policies," Environmental Impact Assessment Review, vol. 31, no. 3, pp. 226-233, 2011.

[51] F. J. Tapiador, K. Burckhart, and J. Martí-Henneberg, "Characterizing European high speed train stations using intermodal time and entropy metrics," Transportation Research Part A: Policy and Practice, vol. 43, no. 2, pp. 197-208, 2009.

[52] S. Eraslan, "A decision making method via TOPSIS on soft sets," Journal of New Results in Science, vol. 4, no. 8, pp. 57-70, 2015.

[53] X. Xu, Y. Lu, Y. Wang, J. Li, and H. Zhang, "Improving service quality of metro systems-A case study in the beijing metro," IEEE Access, vol. 8, pp. 12573-12591, 2020.

[54] M. Janic, "A multi-criteria evaluation of solutions and alternatives for matching capacity to demand in an airport system: the case of London," Transportation Planning and Technology, vol. 38, no. 7, pp. 709-737, 2015. 